\title{
Войтик Т.Н. \\ Специфика ориентировки в схеме собственного тела дошкольников с задержкой психического развития
}

Приводятся результаты экспериментального изучения особенностей ориентировки детей с ЗПР в схеме собственного тела. Описаны качественные своеобразия ориентировки детей на протяжении дошкольного возраста. Определен характер интереса к заданию детей с задержанным развитием, принятие ими задания, характер трудностей, отношение к результату своей деятельности.

Ключевые слова: ориентировка в пространстве, схема тела, восприятиевоспроизведение, задержка психического развития.

Проблема ориентировки в пространстве - одна из значимых проблем психологии человека, так как ориентировка в пространстве является необходимым условием познания, активного преобразования окружающей действительности. В психологии и педагогике накоплен значительный материал по различным проблемам ориентировки человека в пространстве: ощущение, восприятие пространства; пространственные представления; понимание пространственных отношений и т. д. Выявлен генезис ориентировки в пространстве, этапы ее формирования [1, $2,3,4,8,11,12]$. Приведенные в литературе исследования показывают влияние ориентировки в пространстве на овладение детьми основами наук. Являясь необходимым условием успешного познания и активного преобразования действительности, она становится той основой, которая объединяет разные виды учебной и трудовой деятельности.

Исследователи обозначают пространственную ориентировку, как способность человека определять свое местоположение, местоположение других объектов в пространстве, относительно какой либо системы отсчета, дифференцировать направления пространства и свободно передвигаться в нем. В понятие ориентировки включается и изучение свойств, как самого пространства, так и объектов его наполняющих $[2,3,4,11,12$ и др.].

Выделяют два взаимосвязанных и взаимозависимых вида: ориентировка в схеме собственного тела и в окружающем пространстве. Они складываются постепенно: от чувства собственного тела до выработки стратегии поведения в социальном мире [1, 2, 3, 7, 11, 12 и др.]. Генетически ранней формой ориентировки является ориентировка в схеме собственного тела. Известно, что взаимодействие человека со средой включает и само тело человека с характерной для него системой пространственных признаков и отношений. По данным 
исследователей Б.Г. Ананьева, Б.М. Величковского, В.Л. Зинченко, А.Р. Лурия, Е.Ф. Рыбалко, схема тела рассматривается как образ взаимного положения частей тела, возникающий на основе проприоцепции $[1,2,6]$. Согласно представлениям А.С. Батуева, схема тела составляет «основу статического образа тела» и «...представляет собой жесткую систему связей» [5]. Г.Хэд и Г.Холмс рассматривают схему тела как процесс синтеза различных ощущений и формирующихся на этой основе представлений не только о величине, положении и взаимосвязи частей тела, но и о теле как структурном целом [13]. Овладение ребенком схемы тела способствует практическому освоению свойств и направлений пространства.

Задача формирования пространственных представлений - одна из наиболее важных задач дошкольного воспитания, так как именно этот возраст является наиболее сензитивным в развитии ориентировки. Особое значение приобретает эта задача, когда разговор идет о детях с задержкой психического развития.

Проблема развития ориентировки в пространстве на ранних этапах онтогенеза у детей с ЗПР - одна из наиболее актуальных проблем в области специальной психологии. Анализ имеющихся в литературе данных свидетельствует о том, что процесс познания пространства у детей с задержкой психического развития нарушается по всем определяющим направлениям. Отмечается нарушение взаимодействия зрительного, двигательного и тактильного анализаторов, которое складывается с запозданием и долго остается неполноценным. Что в свою очередь отражается на аналитико-синтетической деятельности при переработке разномодальной перцептивной информации.

Э.Ш. Айрапетьянц, О.И. Галкина, 3.М. Дунаева, С.В. Летуновская, Л.А. Пепик, Р.Д. Тригер и др. связывают трудности, возникающие у детей с ЗПР при овладении основами наук, именно с недоразвитием пространственной ориентировки. Дети испытывают затруднения при овладении знаниями по математике, чтению, письму.

Важным направлением изучения ориентировки в пространстве детей с ЗПР является анализ начальных форм ориентировки.

Цель исследования - изучение своеобразия ориентировки в схеме тела детей с задержкой психического развития дошкольного возраста

Гипотезы исследования:

1) у детей с трудностями в обучении наблюдается существенная задержка в сроках формирования умения ориентироваться в схеме собственного тела;

2) дети с ЗПР к концу дошкольного возраста владеют развернутым характером ориентировочно-исследовательских действий;

3) у дошкольников с ЗПР имеются сложности при соотнесении трехмерного пространства с двухмерным.

В эксперименте принимали участие 90 детей с 3ПР церебрально-органического генеза 5-го, 6-го и 7-го годов жизни (по 30 человек). 
Исследование проходило в три этапа.

1 этап - восприятие-воспроизведение движений по подражанию, образцу и словесной инструкции взрослого.

2 этап - восприятие-воспроизведение движений с использованием деревянной дидактической игрушки (человечек с подвижными суставами).

3 этап - восприятие-воспроизведение движений по рисунку-образцу.

Обработка эмпирических данных осуществлялась методами математической статистики и качественный анализ.

\section{Основные результаты}

Данные сравнительного метода математической обработки представлены на рисунке №1.

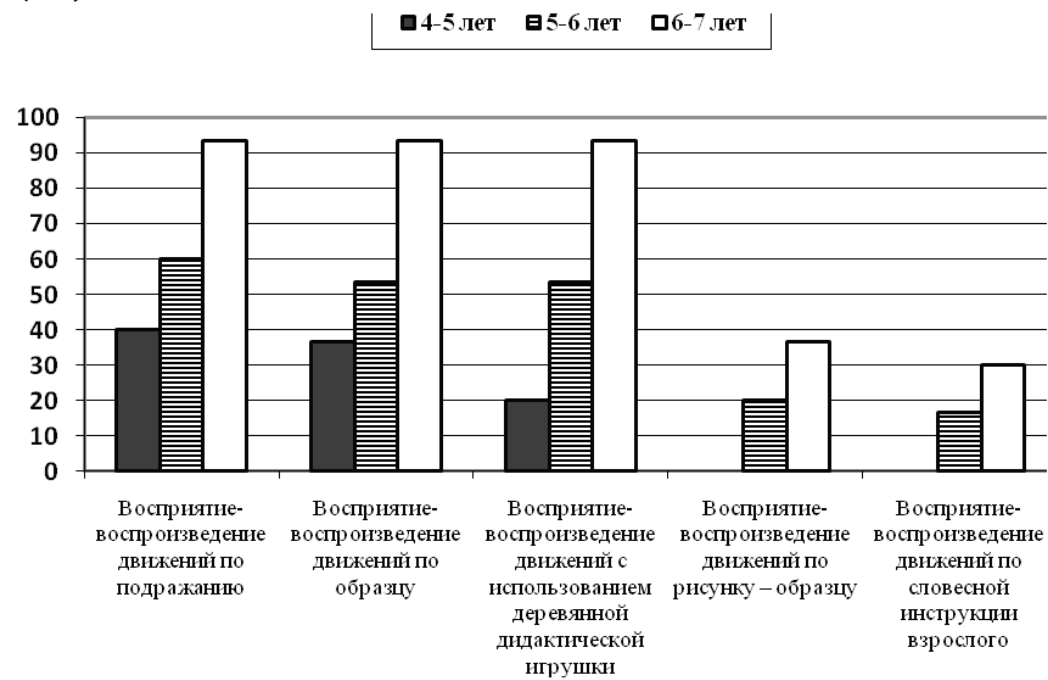

Рис. 1. Ориентировка в схеме собственного тела

(В связи с тем, что дети 4-5 лет с задержкой психического развития не смогли выполнить задание 4 и 5, на гистограмме нет отражения их результатов)

\section{Обсуждение результатов}

Качественный анализ полученных данных выявил, что на 5-м году жизни еще не сформировался стойкий интерес к заданиям на моделирование пространственных отношений. Именно игровой компонент задачи вызывал у детей наибольший интерес, их привлекали игрушки, а не процесс выполнения задания. Как только игрушка им попадала в руки, дети стремились действовать с ней еще до предъявления задания. Сама деятельность детей отличалась нецеленаправленностью, частыми отвлечениями, манипулятивными действиями. 
На 6-м году жизни наблюдалось повышение интереса к заданию. Необходимо отметить, что в этом возрасте были выявлены разнородные результаты. У некоторых детей, так же, как и у детей 4-5 лет не было интереса к заданиям, у других наблюдался неустойчивый интерес (в основном дети реагировали на новизну задания, появление ширмы при действиях по образцу, картинку, игрушку); но были и дети, которые проявили познавательный интерес к заданиям, они старались контролировать правильность выполнения задания, усиливалась их ориентировка в задании, увеличивалась активность (трое детей, обучающиеся в коррекционном учреждении 3-й год). Данная группа детей стремилась рассуждать, комментировать свои действия. Так, например, Катя Я. на предложение выполнить задание, стала интересоваться: «А зачем? Так надо? Как зарядка? Зарядку надо...».

На 7-м году жизни у детей наблюдался устойчивый интерес к заданиям, появлялось стремление лучше его выполнить. На этапе предъявления задания дети внимательно следили за действиями экспериментатора, послушно выполняя работу. Выросла и активность детей. Но при этом можно было увидеть и поверхностное, небрежное выполнение заданий.

Анализ полученных данных говорит и об отсутствии ориентировочного этапа при решении пространственных задач у дошкольников пятого года жизни с задержанным развитием. Они, не вслушиваясь в слова взрослого, начинали действовать сразу, стремились быстрее завершить работу. Качество выполнения задания их не интересовало. Интересен и характер задаваемых вопросов детьми с задержанным развитием. На пятом году жизни у многих детей не возникало ни ориентировочных, ни познавательных вопросов. Они сразу приступали к заданию. Можно было услышать вопрос «Что это?». Но при этом явного интереса у детей не наблюдалось, так как они тут же, задавали такие вопросы как: «Я сделаю и пойду гулять? А все так делали? А мы быстро?» и т.п.. Таким образом, вопрос становился для них как средство вербального общения. На шестом году жизни увеличивается количество детей задающих такие вопросы, как: «Что это? а как? куда?». Дети, обучающиеся в образовательном учреждении третий год, задавали такие вопросы как: «Зачем? почему?» с познавательной целью. На седьмом году жизни ситуация резко меняется, у многих детей появляются дополнительные вопросы. Им было свойственно спрашивать «Зачем? почему? как сделал? куда?» и т.д.. Следует отметить, что авторами Н. Бабич, А.А. Люблинской, E. Hurlock, A. Jersild и др. отмечается у нормально развивающихся сверстников, замедление развития вопросов, к началу школьного возраста количество вопросов в речи детей уменьшается. У детей же с ЗПР, наоборот, к концу дошкольного возраста увеличивается количество вопросов.

Далее необходимо остановиться на характере трудностей, которые испытывали дошкольники с задержанным развитием. На пятом году жизни детям доступно восприятие-воспроизведение движений по подражанию. Реагируя на новизну задания, они сразу приступали к действиям, но при этом в их движениях наблюдалась нечеткость, низкая координированность, невозможность удержания позы. 
Дети не стремились правильно повторить все движения. Наблюдалась и вялость движений, не способность переключиться на другое движение. С увеличением возраста техника выполнения движений меняется, появляется четкость, способность удерживать позу, координированность. Но при этом, некоторым детям была свойственна неспособность завершить действие по первому требованию. Например, Дима Г. (5 л. 11 мес.) после предложения остановиться, продолжал выполнять задание, комментируя: «А я еще так могу». Полученные данные говорят о понимании детьми своей успешности при выполнении задания, которая проявляется в многократном повторении достигнутого результата и в нежелании прекратить деятельность.

Полученные результаты при восприятии-воспроизведении движений по образцу в 4-5 лет, показывают, что третьей части детей доступно понимание образца, при этом у некоторых детей наблюдалось своеобразное замешательство, в результате чего ими допускались ошибки. С пяти лет также как отмечалось ранее, наблюдается улучшение результатов по качественным и количественным показателям.

Восприятие-воспроизведение движений с использованием деревянной дидактической игрушки многим детям пятого года жизни было недоступно. Они не смогли понять смысла поставленной задачи, хотя интерес к игрушке был высок. Вступая в игру с игрушкой, ими не обращалось внимание на предъявляемое задание. Особые трудности были обнаружены в неадекватной передаче действий. Если образец давался в ассиметричном виде, дети заменяли его на симметричный. Так, например Сергей П., увидев на игрушке согнутую правую руку в локте вверх и согнутую левую руку в локте вниз, согнул обе руки в локте вверх. Немаловажен и тот факт, что им была свойственна зеркальность направления движений частей тела. Так Леша Р. (4 г. 2 мес.) вместо расположения согнутой в колене ноги впереди, сгибал ногу коленкой назад. С возрастом ситуация меняется и дети с ЗПР к концу дошкольного возраста практически догоняют своих нормально развивающихся сверстников, как по качеству выполнения задания, так и по количественным показателям.

Общеизвестно, что восприятие или «чтение» пространства, отражённого на плоскости, требует понимания его особой символики, способности устанавливать связь реального и отраженного пространства. Восприятие-воспроизведение движений по рисунку-образцу на пятом году жизни недоступно детям с задержанным развитием. Попытки примеривания своих движений к картинке наблюдалось у детей, которые в коррекционном учреждении обучаются второй год. Приведенные данные говорят об огромной роли оказания ранней коррекционной помощи детям с задержкой в развитии. С возрастом результаты изменяются незначительно, только третья часть детей к концу дошкольного возраста смогли полностью выполнить задание. При этом наблюдается увеличение количества детей, которые соотносили свои движения с картинкой. Так, например Лена Г. (6 л. 4 мес.) рассматривает внимательно картинку, шевелит рукой приближая ее к рисунку, соотносит 
постоянно свое тело с изображением. При этом шепотом подтверждает правильность выполнения задания: «это сюда...так...вот... это так...» и т.п., и только после примериваний выполняет движение.

Как отмечается в литературе, дети с ЗПР отличаются своеобразием формирования речи. Анализируя результаты проведенного исследования, необходимо отметить, что речевые задания вызывали у них особые затруднения. Так, при выполнении задания по словесной инструкции детям пятого года было свойственно непонимание предъявляемого задания, они двигались хаотично, поднимая и опуская руки и ноги не ориентируясь на инструкцию. Четыре ребенка отказались выполнять задание, говоря, что не знают, как необходимо двигаться: «Не могу, не знаю, мы так не делали», и т.д.. С увеличением возраста результаты меняются, но и к концу дошкольного возраста только 30 \% детей смогли правильно выполнить задание.

\section{Выводы}

1. Дети с ЗПР испытывают недостаток в тех способах восприятия, преобразования пространства, которыми свободно владеют их нормально развивающиеся сверстники. У многих детей к концу дошкольного возраста наблюдается развернутый характер ориентировочно-исследовательских действий. Только к концу дошкольного возраста изменяются способы решения поставленных задач: от практического освоения до зрительного соотнесения.

2. У детей выявлена существенная задержка в сроках формирования умения ориентироваться в схеме собственного тела.

3. Отмечены недостатки в развитии основныхдвижений, неточность, некоординированность движений. Только к концу дошкольного возраста, их движения становятся все более осмысленными, управляемыми, слаженными и уверенными. Но и к концу дошкольного возраста нет точного воспроизведения определённого положения тела, формы, амплитуды и направления.

4. Наиболее выраженные нарушения у детей с ЗПР обнаружились в понимании словесной инструкции, которые сохраняются до конца дошкольного возраста, что в свою очередь отражается на формировании пространственных понятий.

5. Выявлены трудности восприятия детьми с 3ПР пространственных отношений, предлагаемых на рисунке-образце. На любом этапе перехода из одной модальности в другую им необходима помощь со стороны взрослого.

\section{Литература}

1. Айрапетъянц Э.Ш., Ананьев Б.Г. Мозговые механизмы и эволюция восприятия пространства и времени. - Л., 1969.

2. Ананьев Б.Г., Рыбалко Е.Ф. Особенности восприятия пространства у детей. - М., 1964. 
3. Ананьев Б.Г. Психология чувственного познания. - М., 1960.

4. Ананьев Б.Г., Рыбалко Е.Ф., Шемякин Ф.Н. Некоторые теоретические проблемы исследования пространственных восприятий и представлений // Вопросы психологии. - 1968. - № 4.

5. Батуев А.С., Таиров О.П. Мозг и организация движений. Концептуальные модели. Л.: Наука, 1978. - 139 с.

6. Величковский Б.М., Зинченко В.П., Лурия А.Р. Психология восприятия. - М.: Изд-во МГУ, 1973.

7. Гаврилушкина О.П., Егорова А.А. Игровая деятельность дошкольников при интеллектуальных расстройствах // Психологическая наука и образование. 2007. - № 5.

8. Комендантов Г.Л. Физиологические основы пространственной ориентировки. - Л., 1959.

9. Лурия А.Р. Высшие корковые функции человека и их нарушения при локальных поражениях мозга. - М.: Изд-во МГУ, 1962.

10. Люблинская А.А. Особенности освоения пространства детьми дошкольного возраста // Формирование восприятия пространства и пространственных представлений у детей. - М., 1956.

11. Рубинштейн С.Л. Основы общей психологии. - М., 1946.

12. Степанов В.С. Асимметрия двигательных действий спортсменов в трехмерном пространстве: автореф. дис.... д-ра пед. наук. - Майкоп, 2001.

13. Head II., Holmes G. Sensory disturbances from cerebral lesions Brain. - 1911/12. V. 34. - P. 102-245. 